\title{
AREDYLD syndrome
}

INSERM

\section{Source}

INSERM. (1999). Orphanet: an online rare disease and orphan drug data base. AREDYLD syndrome. ORPHA:1133

AREDYLD stands for acral-renal-ectodermal-dysplasia-lipoatrophic-diabetes. This syndrome has been described in three individuals, one of whom was born to consanguineous parents. All patients had lipoatrophy, diabetes mellitus, generalized hypotrichosis, ectodermal dysplasia, renal alterations, dental abnormalities and other manifestations. It is probably transmitted as an autosomal recessive trait. 